\title{
Social solidarity, social work and Chinese people
}

\author{
Steven M Shardlow, Keele University, UK \\ Tina L Rochelle, City University of Hong Kong, Hong Kong SAR \\ Contact: Steven M Shardlow, Keele University, Staffordshire ST5 5BG, UK. Email: \\ s.m.shardlow@keele.ac.uk
}

\begin{abstract}
Differences in social solidarity among Chinese in Hong Kong and the United Kingdom have been identified from two linked studies. Significant differences emerged between the two Chinese communities. Notably, respondents in Hong Kong reported a higher sense of belonging to their community, greater engagement with the provision of care for others and made a greater contribution to the lives of others than did UK Chinese respondents. Consideration about construction and delivery of social services is discussed.
\end{abstract}

\section{Social solidarity, social work and Chinese people}

Building social solidarity and social harmony are necessary to advance the quality of social life (Phillips, 2006). The notion of "social solidarity" refers to the degree to which individuals in a society are bound to each other through a sense of mutual interest that enables cooperation and collaboration. As such, some degree of social solidarity is essential for the functioning of a society. Modern thinking about social solidarity originates with Durkheim's (1893) work, The Division of Labour in Society, in which he developed ideas of "mechanical" (links that derive from family or clan) and "organic" (links that derive from complex organisational interaction) forms of social solidarity. For Durkheim, the existence of social solidarity as a phenomenon contributed to understanding the mechanisms that integrate of people within society.

Several strands of enquiry and analysis centred on social solidarity have subsequently developed. First, concerning the legal and contractual relationships between individuals (see for example: Veitch, 2011). As Prosser comments, law is "an external index symbolizing the nature of social solidarity" (Prosser, 2006: 378). Second, focused upon the social, economic and political relationships between individuals, for example: about the importance of social compassion for the management of addictions (Mooney, 2005). Third, how the nature and extent of 
social solidarity in society impacts on the psychological and physical wellbeing of individuals (Hammarström, 2005). For example, Allik and Realo (2004) found in their study of 43 countries, as people become autonomous as individuals, they seem be more dependent on the existence of social solidarity to be able to negotiate their freedoms. Various factors may limit social solidarity. For example, Bay and Pederson (2006) have investigated how social solidarity connects attitudes to immigration and support for basic income provision. The found that a mongst a sample of Norwegians support for income guarantees was reduced when it was possible that these would be given to recent migrants. Hence, not only is "social solidarity" a complex construct, it may also be mediated through other factors such as attitudes to migrants. In this article "social solidarity" is taken to be an indicator of the sense of connectedness individuals feel towards others in their society and hence is a factor that shapes behaviours.

The importance of studying social solidarity lies in its functions and benefits (Cheung and Ma, 2011). Theoretically, social solidarity is useful in maintaining stability and growth (Maloutas and Maloutas, 2004; Berger-Schmitt, 2002), is therefore worth social, political and economic investment. Social solidarity is of concern in contemporary society because of the orientation of public policy in both Chinese and Western societies (Ho and Chan, 2009; White, 2003; Chan and Chan, 2006). Across Europe, in particular, there is increased concern about immigration and ethnic differences, see for example in respect of: Netherlands, Schmeets and te Riele (2014) and Gijsberts et al. (2012); United Kingdom Demireva and Heath (2014). As a result of new waves of migration and greater diversity, there appears to be a pervasive fear that western democratic values will be destroyed by too many immigrants (Vasta, 2010). As such, much of the literature in recent years has focused on the impact of diversity on social cohesion and social solidarity (Letki, 2008; Laurence, 2011), based upon the fear that diversity erodes social cohesion and trust (Putnam, 2007). Fieldhouse and Cutts (2010), in their study comparing levels of cohesion in the US and the UK, suggested that, in England, diversity is but one of a number of equally important factors accounting for variations in cohesion and solidarity, with economic deprivation playing a significant role in the deterioration of civic mindedness. While Laurence and Heath (2008)and Letki (2008) demonstrated that, when the association between diversity and economic deprivation is accounted for, there is no strong evidence that diversity erodes trust.

The provision of social welfare, of which social work is a core element, is predicated upon the existence of a degree of social solidarity at the state level. In the absence of any sense social of solidarity, what motivation would impel government to invest in social welfare? Logical and financial imperatives would incline government to ignore the deprivations of "the other". The fact that this sense of social solidarity is present and underpins the provision of welfare is an essential part of the humane society, however minimal or imperfect. If social solidarity can be 
found embedded in the actions of the state, questions may be asked about particular groups and how their sense of social solidarity interacts with the way that they experience welfare, in particular social work, either as producers or consumers.

Minority ethnic populations may hold distinctive views about the nature and extent of social solidarity, present among their community. Such views may impact on the expectations of minority ethnic community members about the provision of welfare. Consequently, social workers need to develop an understanding about how social solidarity amongst minority ethnic groups may have implications for policy and practice in respect of social work. Central to this need is the expectation that social workers demonstrate cultural competence in their daily practice and deliver services that meet minority group needs. There is an uneasy compromise for the practitioner between the application of generalised skills that encapsulate cultural competence (NASW, 2001), and the need to possess sufficiently detailed knowledge about any particular community. Social workers cannot realistically possess expert knowledge about every minority group that they may encompass. Nonetheless the social work lexicon of knowledge must include some detailed materials about particular minorities. In this article social solidarity and social work are explored in relation to Chinese people.

A range of studies have examined social solidarity among Chinese people. For example, Cheung and Ma (2011) have examined the connections between social solidarity and social harmony. A modest number of such studies have explored aspects of social solidarity in locations where Chinese is a minority ethnic culture. Hwang and Sadiq (2010) have compared the influence of social solidarity on economic social and political integration of the Chinese minority in Malaysia and Indonesia. In the UK, Chan et al. (2007a) have demonstrated that social solidarity among UK Chinese has been weakened by their competitive approach to business in the catering trade. Chan et al. (2007b), based on a study of 100 interviews, found that UK Chinese were strongly oriented to their family, were very much self-reliant, and with limited expectations of social welfare. However, the nature of social solidarity among the UK Chinese community and social connections with the host community has not been well understood. This poses interesting questions for service provision and has implications for policy and practice in respect of health and social work. The present article is focused on the Chinese community in an attempt to better understand social solidarity among this group and how it may impact on social work. Selected findings from two linked studies have been used to explore aspects of social solidarity, among the Chinese in the UK, a minority community, and by comparison with Chinese in Hong Kong, the majority community, to better understand how social workers may meet the needs of the Chinese community in the UK and minority group needs more generally.

\section{Research Aims:}


There is a dearth of empirical research that has examined aspects of social solidarity in one ethnic group by drawing on a comparison of majority and minority communities, such as that by Hwang and Sadiq (2010): there are comparisons across nation states (see for example, Sangiovanni, 2013). Much of the research conducted concentrates on aspects of social solidarity either within majority populations (Chan and Chan, 2008; Cheung and Ma, 2011), or minority populations in the context of the host community (Schuster and Solomos, 2004) With this backdrop, the overall research aim was to undertake a comparative study that would lead to a better understanding of the nature of social solidarity in two Chinese populations, one a majority community in Hong Kong, the other a minority community in the UK.

It was hypothesised that:

(1) There would be a stronger sense of social solidarity among the Hong Kong Chinese (majority community) than among the UK Chinese (minority community). The basis for the hypothesis was suggested by previous research findings that were identified in the published literature for example about the strength of "family" and the extent of economic completion among UK Chinese.

If the hypothesis could be substantiated then the factors associated with social solidarity were to be explored and ideally identified to the extent that the data was sufficiently robust to make this possible. Using outcomes that emerged from the testing of this hypothesis it was anticipated that the findings may contribute to an understanding about how the take up of social work and social care by Chinese people may in part be influenced by the level and nature of social solidarity in the minority Chinese community in the UK. Such findings could then have important messages for the conduct of social work practice.

\section{Methodology}

The research depicted in this article forms part of a series of linked studies conducted by three universities located in Hong Kong, Macau, and the UK. These studies have been conducted to investigate the linked notions of volunteerism, social capital and ageing among Chinese communities in Hong Kong, Macau and the UK. Data from two of the component studies form the empirical grounding for this article. These two linked studies were:

(i) An examination of intergenerational experience in respect to social capital and ageing in Hong Kong.

(ii) An exploration of the experience of UK Chinese in London and Manchester.

The research studies were sited in two countries: 


\section{The United Kingdom}

The Chinese community in the UK has grown significantly in recent decades (Owen, 2006) and constituted the third largest ethnic minority, comprising $0.5 \%$ of the total UK population and around $5 \%$ of the total non-white population (Office for National Statistics, 2011). Hong Kong is the most commonly reported place of birth for Chinese adults aged thirty years and over that live in the UK (Sproston et al., 2000). Although the majority of UK Chinese were born in Hong Kong, an increasing proportion of the UK Chinese community comprises second generation UK-born individuals, in addition to the more recent influx of Mainland Chinese migrants. The UK Chinese ${ }^{1}$ have been perceived to be one of the more successful minority ethnic groups (Owen, 2006). UK Chinese students have been the highest achieving ethnic group in the United Kingdom educational system, while the Chinese have been reported to have one of the highest proportions of individuals employed in professional occupations (Cheng, 1996; Francis and Archer, 2005). However, previous studies have shown that proficiency in the English language varies greatly among Chinese migrants (Ip et al., 2006). Compared to other minority groups in the UK, the Chinese have been viewed as a relatively invisible or silent group in both social and political spheres (Yu, 1991). A feature of Chinese settlement in the UK has been that it is widely scattered and dispersed. This feature has secured their position in market competition with regard to the Chinese catering trade. However, it is this very feature that also has created a social distance from both mainstream society and fragments the local Chinese community in the UK.

\section{Hong Kong}

Hong Kong is one of the most densely populated cities in the world with a population of over seven million. In terms of ethnic composition, Hong Kong is essentially a Han Chinese community, the majority of which is Cantonese or from linguistic groups such as Hakka or Chiu Chow (Census \& Statistics Department, 2011). The remaining population is composed of non-ethnic Chinese, which includes domestic workers, predominantly from Thailand and the Philippines, and ex-patriots predominantly from the UK, Europe and the US, working in the business and finance sectors of the city. In 2006, average life expectancy in Hong Kong reached 85.1 years (Census \& Statistics Department, 2011), while the fertility rate in Hong Kong has been one of the lowest in the world at 1.0 child per female (Chan and Phillips, 2002). Against this background of decreased fertility and increased longevity, Hong Kong is confronted by the challenges posed by an ageing population. The proportion of people aged 65 and above increased from 7.6\% in 1986 to 12.6\% in 2008 (Census \& Statistics Department, 2011). While Hong Kong has been reported as possessing the

\footnotetext{
1 The term 'UK Chinese' is used in this article to refer to those living in the UK with Chinese ancestry; it does not imply anything about nationality.
} 
second highest proportion of older people in the population of the Asian countries; in this it is second only to Japan (Chui, 2008).

\section{UK Sample}

The UK study comprised a convenience sample of 211 Chinese respondents recruited from a selection of Chinese community centres, health centres, and other Chinese social and religious organisations based in London and Manchester. The majority of these organisations were identified using the 'Chinese Community Service Directory'. Organisations were invited to become involved in the study by becoming a recruitment site for participants. All organisations were contacted by one of three methods: letter, telephone, or email. Respondents received a participant information sheet with detailed information describing in lay terms what the study involved. All participants provided informed consent prior to their study participation. The participant information sheet and consent form, as well as the main measure, were presented in a bilingual format. Participants ranged in age from 18 to 79 years; the mean length of UK residency of respondents was 19.54 years (SD = 14.84) (see Table 1). UK respondents self-completed the questionnaire, unless they required help, in which case a member of staff from the relevant Chinese organisation assisted the respondent. As respondents in the UK were recruited from Chinese NGOs and community organisations, the authors acknowledge that the UK sample is not as representative as a randomly selected sample of Chinese immigrants. However, considering the difficulties that have been experienced by researchers in accessing the Chinese community in the UK (see for example, McClean and Campbell, 2003), the recruitment method utilised was considered an effective way of accessing the community. However, this also means that these individuals, who are effectively service users of the organisations involved in the study, may be likely to be more involved with their local Chinese community and are more likely to contribute to their local Chinese community.

\section{Hong Kong Sample}

In Hong Kong, a total of 1170 individuals were recruited to the study via a random household survey conducted territory-wide across Hong Kong. A list of 6,000 addresses territory-wide across Hong Kong, was purchased from the Hong Kong Census Department. Eight interviewers were trained to select and visit households on every $5^{\text {th }}$ line on the list. If the selected household refused to participate or did not respond for up to three visits, it was classified as a rejected case. Approximately, one successful household survey was completed per ten visits. Interviewers completed the questionnaire for all Hong Kong respondents, reading out all the questions. The instrument had a participant information sheet and consent form attached, both of which were presented in traditional Chinese. 
Insert Table 1 about here

The use of different methods for questionnaire completion by the two cohorts of respondents was used as a result of the differences in the size and spread of the two communities in the two countries. In Hong Kong, recruitment was conducted via household survey; while in the UK, Chinese organisations provided an effective way to access the Chinese community.

Instrument

A questionnaire with common elements was used in both Hong Kong and the United Kingdom; this was developed by the research team. The 38-item measure consisted of a number of components, including:

\section{(i) Health \& Functioning}

The first section contained a number of items relating to individual health and functioning. Health status was self-reported using the following item: "Generally speaking, how would you describe your current health state?" Items were rated on a 5-point Likert scale (e.g. $1=$ Very Bad to $5=$ Very Good). A number of items in the measure were related to physical functioning (e.g. "Does your bodily pain interfere with what you need to do in your day to day life?") as well as including items assessing cognitive functioning (e.g. "How many times have you failed to recall a name or word that you are familiar with in the past month?").

\section{(ii) Social Functioning}

The second section contained a number of items relating to societal functioning, such as social solidarity ("In the community in which I live, people care about each other and watch each other's backs"), social identification ("I am part of the society in which I live"), humour ("Do you notice that if you find delight in difficulties, the problem is greatly reduced?"), care for others ("To what extent do you care and help family members to live better?"), contribution to others ("To what extent do you feel that you have contributed towards your family"), society-focused motivation ("It is important for people to help each other"), and trust ("Most of my neighbours are trustworthy") amongst others. Some items were reverse coded. All items were rated on a 7-point Likert scale ( $1=$ Strongly Disagree to $7=$ Strongly Agree).

\section{(iii) Demographics}


The measure also contained a number of demographic items, including items relating to: age, gender, marital status, religion, educational attainment, employment, monthly household income, place of birth, length of UK residence etc.

The instrument was available in two languages Traditional Chinese ${ }^{2}$ and English for the UK sample. This gave the option for participants to complete the measure in either Chinese or English. To ensure consistency of meaning in both language versions, all items were presented in a bilingual format with Chinese and English juxtaposed. The instrument was translated by a bilingual academic, fluent in both Chinese and English, and was back translated by a second bilingual professional to ensure accuracy. The measure was piloted among the local Chinese community to ensure the translation accuracy and authenticity. The instrument demonstrated good internal consistency, with Cronbach alphas $(\alpha)$ of the main components of the instrument ranging from .74 to .91 .

\section{Analysis}

Analysis was performed using Statistical Package for the Social Sciences (SPSS) version 15. T-tests were conducted to compare the mean scores of the variables for the Hong Kong and UK cohorts in terms of societal concern variables. An independent samples t-test was conducted to compare the scores between respondents from the Hong Kong and UK on a number of variables (see Table 2). Linear regression was used to estimate both crude and adjusted odds ratios of association between individual variables and social solidarity amongst UK Chinese and Hong Kong Chinese. In univariate analysis, crude odds ratios were obtained of association of perceptions of social solidarity among Chinese in HK and the UK and numerous variables including: age group; gender; trust; societal distrust; social solidarity; belonging; contribution towards others; care for others; intention to leave Hong Kong/UK; society and self-focused motivation; the importance of local events; social harmony; health and functioning. Univa riate and multivariate linear regression was used to examine predictors of social solidarity for both the Hong Kong and UK sample, adjusting for all potential confounders (see Table 3).

Results

\section{T-Test}

Significant differences were found between the Hong Kong and UK Chinese along the following variables: sense of belonging; care for others; contribution to others; humour; health; and functioning. In terms of sense of belonging, Hong Kong

\footnotetext{
2 Traditional Chinese and Simplified Chinese are two standard sets of Chinese characters of the contemporary written form of the Chinese language. While Traditional Chinese is used in Taiwan, Hong Kong and Macau, Simplified Chinese is officially used in Mainland China, Singapore and Malaysia.
} 
respondents reported a stronger sense of belonging to their local community than their UK counterparts. Hong Kong respondents displayed superior levels regarding care for others, contribution to others and humour, while UK respondents reported better health and functioning.

Insert Table 2 about here

\section{Correlation}

Correlations between social solidarity and a range of other variables including: age group; gender; network size; having people to turn to when in a bad mood; having people to turn to when experiencing financial difficulties; caring for others; contributing to others; health; functioning; life events; humour; social harmony; the importance of local events; society-focused motivation; self-focused motivation; trust; and intention to leave Hong Kong/UK were analysed. Statistically significant odds ranging from -.3 to .85 were found for these associations in both the UK and Hong Kong cohorts.

\section{Predictors of Social Solidarity}

Univariate linear regression was initially conducted to identify variables significantly associated with social solidarity. This was followed by a multivariate model demonstrating predictors of social solidarity among both Hong Kong and UK Chinese. In the multivariate regression model for the Hong Kong sample, the selected variables combined contributed $57 \%$ predictive power towards the model ( $F$ $\left.(8 / 192)=31.17^{* * *}\right)$. Sense of social solidarity was significantly positively associated with being older, being female, good health, social identification, society focused motivation, larger network size and trust. Caring for others was negatively associated with social solidarity (see Table 3 ).

Regarding the UK Chinese sample, again univariate regression was initially conducted, followed by a multivariate analysis. In the multivariate regression model, the selected variables combined contributed $36 \%$ predictive power towards the model $\left(F(8 / 1159)=82.98^{* * *}\right)$. Social solidarity was significantly positively associated with health, care for others, social identification, society-focused motivation, and trust. Network size was negatively associated with social solidarity among the UK Chinese sample (see Table 3).

Insert Table 3 about here 
Among the Hong Kong sample, being female and older was predictive of a sense of social solidarity. Although this was also the case for UK Chinese, this finding was not significant when combined in the multivariate model for UK Chinese. Good health, trust, society-focused motivation, and social identification, in terms of being able to identify with the society in which the individual lives, also proved to be significantly predictive of sense of social solidarity among respondents in both the UK and Hong Kong. Differences in predictors of social solidarity can be observed between Hong Kong and UK respondents in terms of caring for others and network size. Among Hong Kong respondents caring for others was negatively predictive of social solidarity, while among UK Chinese the opposite was true. Network size was positively predictive of social solidarity among Hong Kong Chinese, while the opposite was true for UK Chinese.

\section{Discussion}

\section{Social Solidarity compared among UK and Hong Kong Chinese}

The present study investigated issues relating to social solidarity among a majority Chinese community in Hong Kong, and a minority Chinese community in the UK. Detailed comparative analysis between the minority and majority communities reveals the extent to which UK Chinese see themselves as living in a host community through exploration of differences and similarities in social networks and social solidarity. The results are discussed in the wider context of social change with the view of drawing out some implications for the design and delivery of social services.

In the present study, significant differences emerged between the two Chinese communities, as a majority community in Hong Kong and as a minority community in the UK. The hypothesis was confirmed in that there was a difference between levels of social solidarity between the two communities in that Hong Kong respondents reported a stronger sense of belonging to their community, greater engagement with the provision of care for others and made a greater contribution to the lives of others, than did their Chinese counterparts living in the UK. From this we may tentatively conclude that social solidarity is stronger among Hong Kong Chinese as compared with the UK Chinese. This important finding, seen through the lens of an ageing population both in Hong Kong and the UK, may reflect the greater availability of social resources more readily accessible for those Chinese in Hong Kong as opposed to those in the UK. It is perhaps surprising as social solidarity may be expected to be stronger in a minority than in a majority community. As living in a minority community may incline the members to form strong bonds within that community.

According to present findings older females, both in the UK and in Hong Kong, were more likely to have higher levels of social solidarity than younger respondents and male respondents. Social solidarity was predictive of caring for 
others among UK Chinese, while among Hong Kong Chinese caring for others was negatively predictive of social solidarity. This finding in its elf illustrates the different nature of the two communities in that while Hong Kong Chinese may have a wider and more established network by virtue of being the majority community, UK Chinese may be in a different position. While UK Chinese may feel that caring for close others contributes towards sense of solidarity, among Hong Kong Chinese, caring for close others may be perceived as a hindrance. This is further supported by the finding that network size is positively predictive of social solidarity among Hong Kong Chinese, whilst being negatively predictive of social solidarity among UK Chinese. While the UK Chinese respondents may have a smaller social network by virtue of their status as a minority community, it is suggested that this may impede on perceptions of social solidarity for the UK Chinese community. Findings revealed that network size is predictive of social solidarity among Hong Kong Chinese, further adding to the suggestion of small network size impeding on perceptions of social solidarity among UK Chinese.

Similarities can be observed between the two samples in terms of levels of social solidarity. In both Hong Kong and UK Chinese, health, social identification, society focused motivation and trust were all predictive of social solidarity.

While it can seen from the literature that the UK Chinese are a wellestablished minority group in the UK, the present study demonstrates that the UK Chinese have a strong sense of social solidarity in the host community and are relatively well-settled, despite literature pointing to the invisibility of the community in social and political terms (Yu, 1991) and the scattered living of the community across the UK.

\section{Utilisation of Services}

A sense of social solidarity may impact on use of and satisfaction with social welfare (often elided as health and social care) within the host community (see for example, Chan, Cole \& Bowpitt, 2007). Services may not be provided in ways that the Chinese community can easily understand or access. Findings on reported service underutilisation by UK Chinese have been explained by: differences in world views with regard to health (Green et al., 2006; Gervais and Jovchelovitch, 1998; Sproston et al., 2000; Chau and Yu, 2009) and reported barriers to accessing both social services (Chiu and Yu, 2001) health services (Green et al., 2002). A lack of culturallyappropriate services has been highlighted in mental health provision available to UK Chinese (Li et al., 1999).

There has been a growth in literature that has emphasised how traditional values and practices shape the need for social welfare (often elided as health and social care), and hence social work, among minority ethnic groups. Some of these values impact on the nature and form of social solidarity evident within a community. 
For example, the Chinese have conceptualised health welfare differently to many western societies (Chau and Yu, 2004)(author, 2011): they have been influenced by Confucianism, which has shaped significantly the way in which health and welfare has been practiced (Gervais and Jovchelovitch, 1998; Chau and Yu, 2004)(author, 2010). For instance, the provision of care to elders has been a very highly regarded cultural practice (see for example, Laidlaw et al., 2010: a study of filial piety among Chinese in Beijing and UK). As an illustration of social solidarity, filial piety continues to play an important factor in the life of elders and their families within Chinese culture, both at home and abroad.

\section{Policy and Practice Implications}

A greater proportion of mid-aged and elderly people, combined with a higher life expectancy, imply higher demands on health and social services, in particular services tailored to meet the needs of minority ethnic communities, such as the UK Chinese. Policy initiatives in the delivery of health and social care emphasize the core principle of personalisation that should underpin the delivery of services, i.e., that 'every person who receives support, whether provided by statutory services or funded by themselves, will have choice and control over the shape of that support' (Department of Health, 2006). This implies recognition of the needs of particular communities and the individuals within those communities. Providing services through Chinese speakers may not of itself lead to greater take-up social services by the UK Chinese. It may be necessary to promote community development work that enhances social solidarity among the Chinese community as a pre-requisite for greater use of formal social work services. Central to this is the creation of fora where minority groups can express their needs to policy makers and those that deliver health and social care. The provision of services for any minority community should take account of key characteristics, such as the sense of social solidarity, which may impact on the perceived need for services and the ability of communities to mobilise their own resources. It could be argued that there is a need to develop a social work practice that seeks to promote social solidarity among minority ethnic groups.

\section{Limitations of the Study}

The studies presented in this article have been used to explore knowledge that may impact upon professional social work practice through empirical study of populations with whom social workers are engaged, in particular minority ethnic populations. The research approach taken was novel, a comparison of the same ethic group in two different contexts, one as a minority population the other as a majority population. The findings should be treated with some degree of caution and could best be regarded as indicative given that the two samples, one in Hong Kong and the other in the UK were not matched samples. The sample in Hong Kong was 
random across the territory; the sample in the UK was not. It was focussed on two cities and obtained through various community organisations as mediators.

\section{Conclusion}

While the study did not directly measure the utilisation of welfare services (including social work), the findings indicated that there was a stronger sense of social solidarity among Hong Kong Chinese than UK Chinese. There was some evidence to support the hypothesis that there was a stronger sense of social solidarity among the Hong Kong Chinese (majority community) than among the UK Chinese (minority community). As in Hong Kong respondents indicated a stronger sense of belonging to their community than in the UK. The comparison of the two studies also revealed some differences in the factors associated with social solidarity in the majority Chinese community (Hong Kong) and the minority community (UK). It is known from other studies that UK Chinese underuse welfare services in comparison to other groups. Levels of social solidarity may be a contributory factor as they are related to the integration of people into their community and the structures provided by the state. To enable the development of professional social work practice this line of enquiry about the nature of social solidarity in minority communities (Chinese and others) merits further investigation. 


\section{Research Ethics}

The HK study received ethical approval from xxx Ethics Committee (Ref: XXX).

The UK study received ethical approval from xxx Ethics Committee (Ref: XXX).

\section{Acknowledgements}

The Hong Kong study was supported by a grant from the $x x x$ and the UK study was supported by $x x x$

Names to be added 


\section{References $^{3}$}

\section{Uncategorized References}

Allik J and Realo A. (2004) Individualism-collectivism and social capital. Journal of CrossCultural Psychology 35: 29-49.

Bay A-H and Pedersen AW. (2006) The limits of social solidarity - Basic income, immigration and the legitimacy of the universal welfare state. Acta Sociologica 49: 419-436.

Berger-Schmitt SR. (2002) Considering social cohesion in quality of life assessments: Concept and measurement. Social Indicators Research 58:: 403-428.

Census \& Statistics Department. (2011) Population and Vital Events. Available at: http://www.censtatd.gov.hk.

Chan ACM and Phillips DR. (2002) Policies on ageing and long-term care in Hong Kong. In: Chan ACM and Phillips DR (eds) Ageing and long term care: National policies in the Asia Pacific Region. Singapore: Institute of Southeast Asian Studies.

Chan CK, Cole B and Bowpitt G. (2007a) 'Beyond silent organizations': A reflection of the UK Chinese people and their community organizations. Critical Social Policy 27: 509-533.

Chan CK, Cole B and Bowpitt G. (2007b) Welfare state without dependency: the case of the UK Chinese people. Social Policy and Society 6: 503-514.

Chan E and Chan JC. (2008) Social Cohesion \& Governance Problems in the Tung Chee-hwa Era. Politics \& Government in HK: Crisis UnderChinese Sovereignty.

Chan J and Chan E. (2006) Charting the state of social cohesion in Hong Kong. China Quarterly 187: 635-658.

Chau RCM and Yu SWK. (2004) Pragmatism, Globalism and Culturalism: Health pluralism of Chinese people in Britain. In: Shaw I and Kauppinen K (eds) Constructions of Health \& Illness: European Perspectives. Aldershot: Ashgate, 65-79.

Chau RCM and Yu SWK. (2009) Culturally Sensitive Approaches to Health \& Social Care: Uniformity \& Diversity in the Chinese Community in the UK. International Social Work 52: 773-784.

Cheng Y. (1996) The Chinese Upwardly Mobile. In: Peach C (ed) The Ethnic Minorities of Great Britain: Ethnicity in the 1991 Census. London: Her Majesty's Stationery Office.

Cheung CK and Ma SK. (2011) Coupling Social Solidarity and Social Harmony in Hong Kong. Social Indicators Research 103: 145-167.

Chiu S and Yu S. (2001) An Excess of Culture: The Myth of Shared Care in the Chinese Community in Britain. Ageing \& Society 21: 681-699.

Chui E. (2008) Ageing in Place in Hong Kong: Challenges and opportunities in a capitalist city. Ageing International 32: 167-182.

Demireva N and Heath A. (2014) Diversity and the Civic Spirit in British Neighbourhoods: An Investigation with MCDS and EMBES 2010 Data. Sociology.

Department of Health. (2006) Our health, Our say, Our care: New Directions for Community Services. London: Department of Health.

Durkheim E. (1893/1984) The Division of Labor in Society, New York: The Free Press.

Fieldhouse E and Cutts D. (2010) Does diversity damage social capital? A comparative study of neighbourhood diversity and social capital in the US and Britain. Canadian Journal of Political Science/Revue canadienne de science politique 43: 289-318.

Francis B and Archer L. (2005) British Chinese Pupil's Construction of Gender and Learning. Oxford Review of Education 31: 497-515.

\footnotetext{
${ }^{3}$ Note; References have been formatted using Endnote 17 in SAGE Harvard Style
} 
Gervais MC and Jovchelovitch S. (1998) Health beliefs of the Chinese community in England: a qualitative research study. London: Health Education Authority.

Gijsberts M, van der Meer T and Dagevos J. (2012) 'Hunkering Down' in Multi-Ethnic Neighbourhoods? The Effects of Ethnic Diversity on Dimensions of Social Cohesion. European Sociological Review 28: 527-537.

Green G, Bradby H, Chan A, et al. (2006) "We are not completely Westernised": Dual medical systems and pathways to health care among Chinese migrant women in England. Social Science \& Medicine 62: 1498-1509.

Green G, Bradby H, Chan A, et al. (2002) Is the English National Health Service meeting the needs of mentally distressed Chinese women? Journal of Health Services Research \& Policy 7: 216-221.

Hammarström G. (2005) The Construct of Intergenerational Solidarity in a Lineage Perspective: A Discussion on Underlying Theoretical Assumptions. Journal of Aging Studies 19: 33-51.

Ho SSM and Chan RSY. (2009) Social harmony in Hong Kong: Level, determinants and policy implications. Social Indicators Research 91: 37-58.

Hwang JC and Sadiq K. (2010) Legislating separation and solidarity in plural societies: the Chinese in Indonesia and Malaysia. Nationalism \& ethnic politics 16.

Ip D, Lui CW and Chui WH. (2006) Veiled Entrapment: A Study of Social Isolation of Older Chinese Migrants in Brisbane, Queensland. Ageing \& Society 27: 719-738.

Laidlaw K, Wang DH, Coelho C, et al. (2010) Attitudes to ageing and expectations for filial piety across Chinese and British cultures: A pilot exploratory evaluation. Aging \& Mental Health 14: 283-292.

Laurence J. (2011) The effect of ethnic diversity and community disadvantage on social cohesion: A multi-level analysis of social capital and interethnic relations in UK communities. European Sociological Review 27: 70-89.

Laurence J and Heath A. (2008) Predictors of community cohesion: Multi-level modelling of the 2005 citizenship survey, London: Department for Communities and Local Government.

Letki N. (2008) Does diversity erode social cohesion? Social capital and race in British neighbourhoods. PoliticalStudies 56: 99-126.

Li PL, Logan S, Yee L, et al. (1999) Barriers to meeting the mental health needs of the Chinese community. Journal of Public Health Medicine 21: 74-80.

Maloutas T and Maloutas MP. (2004) The glass menagerie of urban governance and social cohesion: Concepts and stakes/concepts as stakes. International Journal of Urban and Regional Research 28: 449-465.

McClean CA and Campbell CM. (2003) Locating research informants in a multi-ethnic community: Ethnic identities, social networks and recruitment methods. Ethnicity and Health 8.

Mooney GH. (2005) Addictions and social compassion. Drug and Alcohol Review 24: 137-141.

NASW. (2001) NASW Standards for Cutural Competence in Social Work Practice. Washington, DC: National Association of Social Workers.

Office for National Statistics. (2011) 2011 Census. Available at: http://www.ons.gov.uk/ons/index.html.

Owen D. (2006) Demographic profiles and social cohesion of minority ethnic communities in england and wales. Community. Community, Work and \& Family 9: 251-272.

Phillips D. (2006) Quality of life: Concept, policy and practice, London: Routledge.

ProsserT. (2006) Regulation and social solidarity. Journal of Law and Society 33: 364-387.

Putnam RD. (2007) E pluribios unum: Diversity and community in the twenty-first century. The 2006 Johan Skytte Prize Lecture. Scandinavian Political Studies 30: 137-174. 
Sangiovanni A. (2013) Solidarity in the European Union. Oxford Journal of Legal Studies 33: 213-241.

Schmeets H and te Riele S. (2014) Declining Social Cohesion in The Netherlands? Social Indicators Research 115: 791-812.

Schuster L and Solomos J. (2004) Race, immigration and asylum: New Labour's agenda and its consequences. Ethnicities 4: 267-300.

Sproston K, Pitson L, Whitfield G, et al. (2000) Health and lifestyles of the Chinese population in England, London: Health Education Authority.

Vasta E. (2010) The controlling of difference: Social cohesion and the new politics of solidarity. Ethnicities 10: 503-521.

Veitch K. (2011) Social Solidarity and the Power of Contract. Journal of Law and Society 38: 189-214.

White D. (2003) Social policy and solidarity, orphans of the new model of social cohesion. The Canadian Journal of Sociology/Cahiers canadiens de sociologie 28: 51-76.

Yu WK. (1991) The difficulties faced by Chinese people in Britain (in Chinese). Pai Shing 254: 50-51. 